\title{
La concepción espacial en la obra de Foucault
}

\section{The spatial conception in Foucault's work}

\author{
FERNANDO BERESÑAK \\ UBACyT - Instituto de Investigación Gino Germani (Argentina)
}

Recibido: 28-01-2011 Aprobado definitivamente: 13-04-2011

\section{RESUMEN}

En el artículo, objeto de este resumen, trabajaremos una de las temáticas que han sabido encontrar un importante desarrollo en la parte más temprana de la obra de Foucault y que, a pesar de lo que muchas veces se creé, continuó siendo sumamente fundamental para todo su recorrido intelectual: nos referimos a la problemática espacial. Dedicaremos el texto a enmarcar y analizar las críticas y reelaboraciones que Foucault ha formulado en relación a la concepción espacial, así como algunas menciones relativas a las implicancias socio-políticas que la misma arrastraría consigo.

$$
\begin{gathered}
\text { PALABRAS CLAVES } \\
\text { FOUCAULT - ESPACIO - DISTANCIA - RELACIONES DE FUERZA - ORIGEN }
\end{gathered}
$$

\begin{abstract}
In the article object of this summary, we will work on one of the themes that have been subject of a significant development in the earliest part of Foucault's work and which, despite what is often believed, continued to be extremely important for his entire intellectual journey: that is the space problem.We will devote this paper to frame and analyze the criticisms and re-elaborations that Foucault has formulated in relation to the spatial conception, as well as some references to the social-political implications that it would trigger.
\end{abstract}

KEY WORDS

FOUCAULT - SPACE - DISTANCE - POWER RELATIONS - ORIGIN

(C) Contrastes. Revista Internacional de Filosofía, vol. XVII (2012), pp. 65-84. ISSN: 1136-4076

Departamento de Filosofía, Universidad de Málaga, Facultad de Filosofía y Letras

Campus de Teatinos, E-29071 Málaga (España) 
EN EL PRESENTE ARTículo trabajaremos algunas temáticas que han sabido encontrar un importante desarrollo, entre otros lugares, en los textos de literatura de la parte más temprana de la obra de Foucault. Como es sabido, Foucault se ha distanciado y ha sido crítico de su «etapa literaria». Aquel posicionamiento, y el hecho de que el texto que será clave en lo sucesivo se corresponde con el año 1963, nos lleva -necesariamente- a realizar algunas aclaraciones al respecto.

En primer lugar, resulta fundamental matizar ese distanciamiento, en el sentido de que el mismo no necesariamente refiere a todos y cada uno de los textos de aquella etapa, así como tampoco a todas y cada una de las temáticas que allí se trataban (las cuales, por cierto, correspondían a la más compleja diversidad). Es claro que el distanciamiento y la actitud crítica que luego de un tiempo Foucault desplegará, refiere a cierta expectativa respecto de las posibilidades que ofrecería cierta experiencia del lenguaje. A pesar de las fuertes implicancias de ese posicionamiento, el mismo no agota la ya mencionada compleja variedad de temáticas en juego.

Eso es justamente lo que ocurre con la específica temática que nosotros trabajaremos en lo sucesivo; a saber, la concepción espacial. Esta problemática, si bien consigue un importante despliegue en el texto de 1963 que veremos a continuación, sigue siendo central para Foucault sobre finales de la década de 1960, tal como lo demuestran las conferencias pronunciadas en 1966 (El cuerpo utópico y Las heterotopías) y 1967 (Espacios diferentes). Asimismo, tal temática en absoluto quedará en su período de 1960; volvemos a encontrarnos con ella en 1978, en la entrevista conocida bajo el nombre de La escena de la filosofía, en donde retoma aquellas cuestiones (de hecho, retoma la conferencia de 1967) con una mirada para nada crítica; por el contrario, reivindica la importancia de dicha temática y su preocupación por la misma en aquél momento. Finalmente, y sin entrar en los detalles del análisis espacial que lleva adelante en su libro de 1975, Vigilar y castigar, en mayo de 1984 se dedicará a corregir un texto de 1978, La vida: la experiencia y la ciencia, a los fines de que vuelva a ser publicado reflejando su actual pensamiento de la cuestión; allí, es necesario decirlo, no hay modificaciones sustanciales sobre la temática de la espacialidad.

Más allá de que el texto que trabajaremos corresponde al año 1963 y a una dimensión literaria de la obra de Foucault, el mismo no deja por ello de resultar sumamente útil a los fines de iluminar algunas temáticas que se mantendrán a lo largo de toda su obra como lo es aquí lo concerniente a la especialidad. ${ }^{1}$

1 Dada la abundante bibliografía que sostiene la división de la obra de Foucault en tres -o hasta cuatro- períodos («primeros estudios», -pero sobre todo- «arqueológico», «genealógico» y «ético»), y tomando en consideración el debate que existe en torno a si es legítimo e 
Dedicaremos el texto, entonces, a enmarcar y analizar las críticas y reelaboraciones que este filósofo francés ha formulado en relación a la concepción espacial, así como algunas menciones relativas a las implicancias socio-políticas que la misma arrastraría consigo.

En noviembre de 1963 (en el número 198 de la revista francesa Critique) aparece el texto de Foucault denominado Distancia, aspecto, origen. ${ }^{2}$ Más allá de su estrecha relación a los primeros trabajos del grupo de la revista Tel Quel y especialmente a la obra del escritor Alain Robbe-Grillet, este texto se presenta a sí mismo como una crítica a las posibilidades del lenguaje. ${ }^{3}$

interesante tomar con el mismo grado de importancia las primeras obras de Foucault que aquellas correspondientes a lo que algunos llaman su período más maduro, cabe formular las siguientes aclaraciones:

La división de la obra de Foucault en tres - o cuatro- períodos sólo cobra eficacia a los fines de poder sistematizar y explicar los lineamientos más generales de sus textos, pero no se corresponde con una división literal de la misma. La especificidad y el detalle de esta obra sólo puede observarse si tomamos en consideración las reformulaciones, matices y curvas teóricas que Foucault ha realizado sobre lo que él ha defendido hasta sus últimos días como la continuidad de un proyecto -vale aclarar, bastante amplio.

Es importante afirmar que esta continuidad refiere a los aspectos de método y a los intereses más generales de este autor -y no a los enfoques temáticos, períodos históricos o cuestiones de método que se corresponden con las necesidades específicas de cada trabajo.

No pretendemos afirmar que la arqueología y la genealogía constituyen dos palabras distintas para referir al mismo método, ni que Vigilar y castigar tiene el mismo enfoque que Historia de la sexualidad 2 o que Las palabras y las cosas; sin embargo, al menos desde la publicación de Historia de la locura en la época clásica en 1961, todos estos trabajos sí comparten el proyecto más general del método foucaulteano, a saber: encontrar el modo de funcionamiento, la tipología y la operatividad enunciativa de lo que él llamo los ámbitos de la cientificidad (a partir de textos teóricos, como los de Descartes y los analizados en Las palabras y las cosas) y de las instituciones (a través de las actas, reportes y reglamentos de las instituciones), así como desenmarañar y estudiar las diversas formaciones históricas que hacían ello posible (aunque, vale aclarar, este último punto será desarrollado o logrado con mayor agudeza en la década de 1970, forjado a partir de un interesante intento previo que fuera plasmado en La arqueología del saber).

Por otra parte, tal como se verá en el cuerpo del texto, Foucault continuó trayendo a colación, durante toda su obra, los temas espaciales que aquí retomamos. Todo lo cual nos indica que si bien Foucault pudo haber reformulado algunas cuestiones en los años sucesivos, no tendría sentido dejar a un lado los textos de su etapa más temprana, ya que fueron sumamente importantes para sus trabajos posteriores.

$2 C f$. M. Foucault, «Distancia, aspecto, origen», en M. Foucault, De lenguaje y literatura. Barcelona: Paidós, 1996, pp. 165-179.

3 Éste será el único texto «literario» que se tome dentro de la obra foucaulteana. Las razones de esta elección es que en él se pueden observar ciertas metáforas sobre la noción de 
En ese texto, podemos encontrar algunos pasajes que lo muestran a Foucault indagando modos posibles en el que el lenguaje podría conformar una imagen de la articulación discursiva, afrontando el problema de mencionar lo que el lenguaje al cual estamos acostumbrados a habitar no logra enunciar.

Pero, ¿qué es eso que el modo en que hacemos uso del lenguaje actualmente no permitiría enunciar? Foucault respondería a esta pregunta en diversos momentos de su obra, diciendo que lo que no pudo ser dicho es la distancia; ese espacio (usualmente comprendido como un vacío) que nos permite comprender cortes, rupturas, transformaciones, regiones separadas, épocas, períodos enunciativos, dos tiempos que simulan ser distintos y estar separados por un origen -antes entendido como un «eje con forma de cuchillo». Debemos decir, entonces, que bajo formas, concepciones y dimensiones diversas, la distancia en el origen es lo que no pudo ser dicho.

Leamos a Foucault a través de una extensa cita, la cual se justifica por el maravilloso estilo literario que despliega y porque permite captar, en toda su especificidad, lo que aquí intentamos expresar: «Así pues, nos las habemos con un espacio desplazado, a la vez retraído y adelantado, nunca del todo al mismo nivel; y, a decir verdad, en él no es posible ninguna intrusión. [...] Regiones separadas, pero, ¿mediante qué? Sin lugar a dudas, nada más que por una distancia, su distancia; un vacío imperceptible pero que nada puede reabsorber, ni rellenar, una línea que no se cesa de saltar por encima sin que se borre, como si, por el contrario, fuera cruzándola sin parar como se la marcara aún más. Porque este límite no aísla dos partes del mundo: un sujeto y un objeto o las cosas frente al pensamiento; es más bien la relación universal, la muda, laboriosa e instantánea relación por la que todo se anuda y se desanuda, por la que todo aparece, centella y se extingue, por la que en el mismo movimiento las cosas se dan y se escapan. [...] Pero lo esencial en esta distancia milimétrica como una línea no es que excluya, lo esencial es más fundamentalmente que abre; libera, por ambos lados su lanza, dos espacios que poseen el secreto de ser el mismo, de estar por completo aquí y allá; de estar donde están a distancia; de ofrecer su interioridad, su tibia caverna, su rostro de noche, fuera de sí mismos y, sin embargo, en la más cercana vecindad. En torno a este invisible cuchillo todos los seres giran como sobre un eje». ${ }^{4}$

origen que nos resultan sumamente esclarecedoras para nuestros objetivos. Esperemos que el análisis de este texto permita la revisión de esa premisa que permite separar los textos por temáticas (literarios o de otra índole) sin más; sobre todo, en aquellos que no la consideran como una mera operación de sistematización u orden de su obra, sino que la entienden como determinante en lo que respecta a los supuestos límites para el acceso a la misma, y su respectivo análisis.

4 Ibid, pp. 168-169. 
Es ese extraño «divisor» el que, más que multiplicar las diferencias, anuda un secreto -tal vez hoy olvidado-; a saber: las correspondencias entre determinadas concepciones del tiempo y las formas que en él habitan. El problema será entonces encontrar el modo en que estas formas se hacen presentes y se distribuyen logrando sus respectivas temporalidades, de manera tal que sea posible devolverlas a su complejo lugar.

Para eso, en la siguiente cita del mismo texto, Foucault mostrará algunas ideas de un pensamiento que luego -en el apartado denominado «Método» de Historia de la sexualidad 1- desarrollará: «Esta torsión [la distancia que separa; el origen] tiene la propiedad maravillosa de restablecer el tiempo: no para hacer que cohabiten sus formas sucesivas en un espacio de recorrido [...] sino para dejarlas llegar más bien en una dimensión sagital -flechas que atraviesan el espesor ante nosotros. O, más aún, ellas vienen fuera de quicio, no siendo ya el pasado el suelo sobre el que estamos ni una ascensión hacia nosotros bajo las especies del recuerdo, sino por el contrario, viniendo inesperadamente a pesar de las más viejas metáforas de la memoria, arribando desde el fondo de la distancia tan próxima y con ella». ${ }^{5}$ Tal como lo enuncia Foucault, es ese lugar -en el origen- quien establece -o reestablece- el tiempo y sus formas, distribuyéndolas.

Lo llamativo de esta cita es la dimensión un tanto extraña desde la que provienen esas formas que aparecen en el tiempo; recién se dijo que vienen inesperadamente desde el fondo de la distancia. ¿Qué quiere decirnos Foucault a través de este enunciado? ¿Acaso nos remite a una posible teoría de la relación, la cual intentaría explicar el modo en que todo surge desde ella (desde su profundidad, entendiendo a ésta como la más pura exterioridad), y no ya desde el hombre y su razón? Y, si así fuera, ¿cuál sería el lugar que el ser humano ocuparía en esta lógica? Antes de contestar estos interrogantes, debemos seguir analizando algunos párrafos de este texto para luego ponerlos en relación con otros momentos de la obra foucaulteana.

El siguiente enunciado, aparentemente literario, resulta similar a lo que -al parecer-fue un principio metodológico que gobernó todas las investigaciones foucaulteanas: «No se descifran signos a través de un sistema de diferencias; se siguen isomorfismos, a través de un espesor de analogías». ${ }^{6}$ En vez de tratar de comprender un concepto o un objeto a través de lo que «no es» (sistema de diferencias), se lo entenderá captando la funcionalidad específica de un espesor espacio-temporal tejido por determinadas relaciones y, luego, siguiendo a éstas en su recorrido bi-direccional con respecto a otro espacio-tiempo funcional (el recorrido sería de un «elemento» a otro, y viceversa). Es así que resulta impor-

5 Ibid.

6 Ibid,pp. 170-171. 
tante destacar que en los espacios donde se conforman los objetos de estudio foucaulteanos no hay posibilidad de concebir «elementos»-libres-, sin captar asimismo las relaciones que los constituyen.

Lo interesante de esta propuesta (la cual intenta captar el modo en que las prácticas discursivas operan, para luego poder definirlas a través de su funcionalidad, en vez de hacerlo a través del sistema de diferencias), es que nos intenta alejar de un vocabulario metafísico al cual estamos acostumbrados (aunque, tal vez, introduciéndonos en otro, pero con un estilo diferente; problema que dejaremos para otra ocasión); permitiéndonos observar aquello que antes se mantenía oculto: espacialidades donde las distancias están compuestas por relaciones inteligibles.

Este recorrido bi-direccional de analogía controlada, que Foucault nos llama a realizar sobre las funciones de los diversos «objetos de estudio», nos permite comprender la lógica mayor que gobierna la conformación de determinadas tramas de relaciones históricas. Es preciso recordar que aunque «la historia hiciera que aparecieran sucesivamente sus trayectos, sus cruces y sus nudos, esta red puede y debe ser recorrida por la crítica siguiendo un movimiento reversible (reversión que cambia algunas propiedades; pero que no impugna la existencia de la red, puesto que es precisamente una de sus leyes fundamentales)». ${ }^{7}$

Ahora bien, Foucault va a lanzar una observación clave que no sólo ilumina su modo de comprender la historia, sino también -y sobre todo- algunas de sus ideas metodológicas más profundas: «iY si lo ficticio fuera precisamente no el más allá ni el secreto íntimo de lo cotidiano, sino el trayecto de flecha que nos golpea los ojos y nos ofrece todo lo que aparece? Entonces lo ficticio sería además lo que nombra las cosas, las hace hablar y les da en el lenguaje su ser compartido ya por el poder soberano de las palabras [...]. Así pues, no hay que decir que la ficción es el lenguaje: el giro sería demasiado simple, aunque nos resulte familiar en nuestros días. Hay que decir, con más prudencia, que hay entre ellos una pertenencia compleja, un apoyo y una impugnación; y que, mantenida durante tanto tiempo como pueda conservar el habla, la sencilla experiencia que consiste en coger una pluma y escribir desprende (como quien dice: liberar, desenterrar, desempeñar una prenda o retirar una promesa) una distancia que no pertenece ni al mundo, ni al inconciente, ni a la mirada, ni a la interioridad, una distancia que, en estado desnudo, ofrece una cuadrícula de tinta y además un encabalgamiento de calles, una ciudad naciente, ya aquí desde hace mucho tiempo [...]. Y si finalmente se me pidiera que definiera lo ficticio, diría, desmañadamente: la nervadura verbal de lo que no existe, tal como es». ${ }^{8}$

$7 \quad$ Ibid, pp. 172.

8 Ibid,pp. 173-174. 
Si bien entre la modalización ficcional y el habla existe una compleja relación -que no nos detendremos a analizar por el momento-, lo interesante es poder ver lo que dicha operación produce: una distancia $-\mathrm{y}$ su entramado relacional- que no pertenece a aquello que supimos captar con la conceptualidad hasta ahora disponible (no pertenece ni al mundo, ni al inconciente, ni a la mirada, ni a la interioridad).

Se trata de una distancia que no pertenece al vocabulario de universales a-históricos y, nos atreveríamos a decir, que tampoco pertenece a lo que comúnmente podemos entender por objetos tales como los elementos materiales corpóreos (de los que el «hombre» o el «mundo» serían algunos ejemplos).

Es inevitable, entonces, abordar la definición que Foucault ofrece sobre la ficción, a saber: la nervadura verbal de lo que no existe, tal como es; «lo que no existe, tal como es» (así lo enuncia). La ficción ofrece el nacimiento o el surgimiento a algo que, de alguna manera, ya estaba allí, desde hace tiempo, pero sin forma histórica. Foucault mismo trata de especificar el estado de este objeto ficcional «sin forma histórica», haciendo referencia a una ciudad, a una cuadrícula de líneas de tinta y a un encabalgamiento de calles, en definitiva a una espacialidad que construye el lenguaje.

Es sumamente revelador el modo en que Foucault intenta concebir la ficción, sobre todo si tomamos en consideración la fuerte influencia de Nietzsche (quien concebía al conocimiento y a la verdad como una especie de ficción que escondía una mentira). ${ }^{9}$ Ahora bien, si intentar huir de esa mentira conduce a una aporía -o, mejor dicho, no conduce a ningún lugar lógicamente legítimo-, se comprende porque Foucault no intentará alcanzar una verdad, ni tampoco simplemente hacer una crítica, sino más bien construir una forma de saber ficcional que sea más audaz, completa y eficaz.

En ella, no se tratará solamente de poder contener un panorama más amplio o una mayor cantidad de elementos, sino también, y sobre todo, de hacer posible la aparición de las relaciones que constituyen a estos últimos en el campo espacial del objeto de estudio en cuestión. Se trata de intentar generar un saber que ya no pueda realizar afirmaciones sobre los aparentes «elementos», sino que haga aparecer la matriz de relaciones y sus múltiples funciones, conformando las ficciones.

Bajo esta óptica es factible comprender la radicalidad de lo que está en juego en el proyecto foucaulteano; así lo enuncia Foucault: «Borraré, para dejar esta experiencia en lo que es (así pues, para tratarla como ficción, puesto que, es bien sabido, ella no existe), borraré todas las palabras contradictorias por las que

$9 C f$. F. Nietzsche, Sobre verdad y mentira en sentido extramoral. Madrid: Tecnos, 2006. 
fácilmente se la podría dialectizar: enfrentamiento o abolición de lo subjetivo y de lo objetivo, de lo interior y lo exterior, de la realidad y lo imaginario. Habría que sustituir todo este léxico de la mezcla por el vocabulario de la distancia [...]; y todo lenguaje que en lugar de olvidar esta distancia se mantenga en ella y la mantenga en él, todo lenguaje que hable de esta distancia adelantándose en ella es un lenguaje de ficción». ${ }^{10}$

Es sabido que Foucault concibe su metodología como un artificio y una estrategia, ${ }^{11}$ dejando en claro su cercanía al juego del lenguaje ficcional. Artificio, estrategia y ficción, aquí, se presentan en un juego recíproco para comprender el lugar que viene a ocupar su concepción del dominio histórico-filosófico. Foucault encuentra que el vocabulario conceptual al que estamos acostumbrados (dicotomías como subjetivo y objetivo, interior y exterior, realidad e imaginario; y los universales a-históricos), todo ese vocabulario de la mezcla -como dice él-, no resulta útil e impide la comprensión cabal de aquello a los cual nos intentamos referir (y, así, lo transforma todo).

Es por eso que intentará construir lo que llama un vocabulario de la distancia, un vocabulario conceptual que pueda hacer presente la espacialidad conformada por las relaciones y funciones entre las diversas formaciones o aspectos históricos, y que no permita olvidar la distancia, sino que intente permanecer en ella, ya que sólo así se podrá habitar algo así como un saber (con todas sus implicancias filosófico-políticas) de modo radicalmente distinto.

Foucault encontrará en la noción de origen el lugar donde se hace visible toda esta compleja serie de articulaciones dicotómicas y un tanto engañosas (o, al menos, insuficientes para los fines que pretenden). Es en el origen donde -parecería- podemos encontrar el problema fundamental entre el pensamiento y el lenguaje. En 1963, Foucault nos decía al respecto que «en la horca donde estamos atrapados se dibuja un espacio en el que el estructuralismo actual deposita sin que quepan dudas de ello la mirada de superficie más meticulosa. Pero si se examina este espacio, se le pregunta de dónde nos viene, él y las mudas metáforas sobre las que obstinadamente reposa, veremos quizás dibujarse figuras que no son ya las de lo simultáneo: las relaciones del aspecto en el juego de la distancia». ${ }^{12}$

Como se deja entrever en este texto, y más precisamente en el capítulo noveno de Las palabras y las cosas (al cual remito), Foucault presenta cierta expectativa en cuanto a la posible desaparición o desgarramiento de la figura del hombre: dicha «esperanza» consiste en que, de recomponerse el lenguaje y

10 M. Foucault, loc. cit., pp. 174-175; la cursiva nos pertenece.

11 Cf. R. Pol-Droit, Entrevistas con Michel Foucault. Buenos Aires: Paidós, 2008, pp. 73-74.

12 M. Foucault, loc. cit., p. 179. 
lograr así realizar un vocabulario que pueda enunciar esa distancia cuyo entramado de relaciones está en constante movimiento, tal vez sea posible obtener para los tiempos venideros una nueva manera de llevar a cabo la experiencia, así como también otra figura para el ser humano. ${ }^{13}$

Vemos entonces como, en 1963, Foucault iba conformando algunas ideas relativas a la noción de origen, del modo en que el origen surge y toma forma, de un origen que no refiera ni a un sujeto, ni a una conciencia, ni a un inconciente, ni a una interioridad, ni a una exterioridad, ni a un mundo, ni a una realidad, ni a una imaginación. Tal como lo citamos anteriormente, el origen, lejos de ser un punto, es una distancia compuesta por una matriz de relaciones siempre en movimiento, en donde - provenientes de su «profunda exterioridad»- surgen formaciones o aspectos históricos, ya ahí, con su extraña presencia, en la relación, en una peculiar latencia, desde hace mucho tiempo.

Foucault sólo se había encargado de atacar todas las concepciones que circulaban sobre la noción de origen; si refería al origen positivamente, sólo hacía mención de una «apertura» a un cambio. En los siguientes dos brillantes párrafos de Las palabras y las cosas se verá que intenta clarificar esta situación: «más que cicatriz señalada en un instante cualquiera de la duración, [el origen] es la apertura a partir de la cual puede reconstituirse el tiempo en general, deformarse la duración y hacer su aparición las cosas en el momento que les es propio [...]. Se ofrece así una tarea al pensamiento: la de impugnar el origen de las cosas, pero impugnarlo para fundamentarlo, reencontrando el modo de acuerdo con el cual se constituye la posibilidad del tiempo - este origen sin origen ni comienzo a partir del cual todo puede nacer. Tal tarea implica el poner en duda todo aquello que pertenece al tiempo, todo aquello que se forma en él, todo aquello que se aloja en su elemento móvil, de manera que aparezca el desgarrón sin cronología y sin historia del cual proviene el tiempo». ${ }^{14}$

Así se hace visible el modo a través del cual Foucault pretende abordar la cuestión del origen: allí, en el lugar donde se oculta esa problemática noción, se despliega el campo donde el nacimiento de las cosas puede acontecer. Este terreno fértil, que en absoluto se reduce a un punto, sino que más bien refiere a

13 Cf. ibid, pp. 178-179. Asimismo, cf. M. Foucault, Las palabras y las cosas. Una arqueología de las ciencias humanas. Buenos Aires: Siglo XXI, 2003, pp. 330-331.

Otra razón más para revalorizar el trabajo «temprano» de Foucault es el hecho de que el libro que lo llevo a obtener mayor reconocimiento académico, Las palabras y las cosas, es el resultado de la extensión -sugerida por Jean Hyppolite y Maurice Gandillac- de su tesis complementaria de doctorado, titulada Introducción a la Antropología de Kant (Génesis y estructura de la Antropología de Kant), la cual fue elaborada entre 1959 y 1960 en Hamburgo (Cf. M. Foucault, Una lectura de Kant: introducción a La antropología en sentido pragmático. Buenos Aires: Siglo XXI Editores, 2009, p. 33).

14 M. Foucault, Las palabras y las cosas, p. 323. 
una distancia -a un modo de concebir el juego del mundo-, es el lugar propio donde situar el pensamiento de la historicidad y la temporalidad. Bajo esa concepción que despliega la noción de origen es posible hacer inteligible aquello que pertenece -que forma parte; que se aloja- en el tiempo, aunque con las especificidades que le son propias (las cuales pronto analizaremos). Esta particular manera de concebir la temporalidad y la historicidad del juego del mundo sólo es posible, para Foucault, poniendo en suspenso aquello que se nos presenta como evidente bajo las concepciones que aún hoy nos gobiernan.

Las precedentes palabras no pueden ser comprendidas en su radicalidad (y menos aún sus fuertes implicancias políticas) si no se las concibe como un eco de aquella reflexión que el filósofo francés nos ofrecía sobre los tiempos venideros, a saber: «[...] el fin del hombre es el retorno al comienzo de la filosofía. Actualmente sólo se puede pensar en el vacío del hombre desaparecido. Pues este vacío no profundiza una carencia; no prescribe una laguna que haya que llenar. No es nada más, ni nada menos, que el despliegue de un espacio en el que por fin es posible pensar de nuevo». ${ }^{15}$

Es esta espacialidad la que intenta dibujar Foucault; aunque en este momento de su obra aún no estén presentes -o no haya encontrado- todos sus elementos. No es casualidad que, en Las palabras y las cosas, asocie fuertemente la posibilidad de una nueva figura del hombre a una nueva manera de concebir el lenguaje y, a su vez, proponga sustituir el vocabulario de la mezcla por un vocabulario que enuncie la distancia -concibiéndolos en el entramado de relaciones que los constituye-, pudiendo enunciar la matriz que configura la historia.

En definitiva, Foucault requiere, exige e intenta elaborar una nueva concepción de la imagen del mundo. Bajo la perspectiva que venimos desarrollando en este texto, las siguientes palabras enunciadas en 1963 se transforman en una de las aristas fundamentales (y poco trabajadas) del campo abierto por Foucault para poder pensar el despliegue de aquel espacio: «la repartición del tiempo -de los tiempos- se hace no imprecisa en sí misma, sino enteramente relativa al juego del aspecto y gobernada por él -por este juego en que se trata de la digresión, el trayecto, la venida y el retorno. Lo que instaura secretamente y determina este tiempo indeterminado es, pues, una red más espacial que temporal; habría aún que quitarle a la palabra espacial lo que la emparenta con una

15 Ibid, pp. 332-333; la cursiva nos pertenece. Se vuelve imperioso admitir que este entramado de reformulaciones metodológicas y de posibles propuestas para una nueva figura del hombre merece una atención especial y un esclarecimiento más eficaz del que se ofrece aquí. Aunque dejaremos dicha tarea para otra oportunidad, no nos privaremos de remitir al lector al siguiente libro: H. L. Dreyfus y P. Rabinow, Michel Foucault: más allá del estructuralismo y la hermenéutica. Buenos Aires: Nueva Visión, 2001 (especialmente los capítulos 2 y 4 de la «Parte I. La ilusión del discurso autónomo»). 
mirada imperiosa o una andadura sucesiva; se trata más bien de ese espacio, por debajo del espacio y el tiempo, que es el de la distancia». ${ }^{16}$

El porvenir de la política depende, en gran medida, si no absolutamente, de lo que el ser humano haga en esta espacialidad, del modo de concebirla y experimentarla cada vez; incluso de la posibilidad de encontrar una reformulación a esta problemática.

Será preciso observar el modo en que la investigación de Foucault intentó trazar algunos caminos en sintonía con esa idea.

Para ello, a partir de aquí, tomaremos especialmente en consideración el modo en que Foucault afrontó las diversas problemáticas que afloran alrededor de la cuestión del origen y de esta espacialidad (entendiéndola, ahora, como previa al espacio, recortado por una mirada soberana, y al tiempo, distribuido y acumulado en forma cronológica). De aquí en más, indagaremos en las fuerzas, las dinámicas, las lógicas, -en definitiva- las características que habitan en esa espacialidad, y que ella hace visible.

III

En el apartado relativo al «Método», que se encuentra en el capítulo cuarto de Historia de la sexualidad 1 (cuya publicación data del año 1976), encontramos una precisa descripción de la lógica y de las especificidades de esta espacialidad, así como algunas reflexiones -aparentemente contradictorias- sobre el lugar que ocupa el ser humano en la misma (como ya veremos, no es en vano aclarar que estos señalamientos se encuentran en el capítulo dedicado al desarrollo del dispositivo, que, en este libro, será el dispositivo de la sexualidad).

Si bien Foucault dedica gran parte de ese texto a explicitar qué es lo que entiende por poder, en esa descripción es necesario comprender también la presencia implícita de su concepción ontológica más profunda. ${ }^{17}$ Es sabido que ésta será utilizada para comprender el funcionamiento de la esfera socio-política: se trata de una especie de «cifra de inteligibilidad del campo social»..$^{18}$

16 M. Foucault, «Distancia, aspecto, origen», loc. cit., pp. 176-177; la cursiva y la negrita nos pertenecen.

17 La no contradicción de los términos empleados entre la concepción metodológica que, por un lado, Foucault dejó entrever en los trabajos «tempranos» que hemos analizado en el apartado anterior y, por el otro, aquella otra que formuló de manera más clara en el apartado de «Método» de Historia de la sexualidad 1, así como - tal como lo veremos- la sólida conexión de la concepción espacial -y ontológica- que existe entre ambos textos, ofrece -todo ello- claras razones para continuar sosteniendo que, situados en determinadas líneas o perspectivas temáticas, la obra de Foucault también puede responder a un proyecto común y general -aunque ello no se corresponda a una necesidad, ni a la única perspectiva posible.

18 M. Foucault, Historia de la sexualidad 1: la voluntad de saber. Buenos Aires: Siglo 
En tanto que las relaciones de poder y de saber se esparcen por todo el entramado socio-político, tejiendo matrices de relaciones -o dominios- que forman parte de los dispositivos, se podría afirmar que, cuando Foucault describe las relaciones de poder y de saber, no hace sino calcar el diagrama de la lógica que, según él, estaría esparcida y operando en esa espacialidad a la cual venimos refiriendo: una especie de ontología - política- de lo actual.

Así como la noción de origen ofrece una imagen del modo en que las prácticas-discursivas aparecen en su especificidad-delineando sus propias características y sus temporalidades-, la concepción foucaulteana del poder-saber pretende agregar a esa imagen el dibujo de la dinámica que en ella opera.

Debemos prestar atención a los momentos en donde se crea, se inventa o se origina aquello que aparece y circula en el mundo, en tanto que es en ellos (en la «discontinuidad», en el «origen») donde se hace visible la lógica y las características del funcionamiento de la espacialidad de la distancia.

Tomando en consideración y analizando los diferentes momentos en los cuales Foucault trató de especificar lo que entiende por relaciones de fuerza -o relaciones de poder y de saber-, pudimos captar que las siguientes son sus características primordiales:

- Omnipresentes: provienen de todos lados.

- Inmanentes: sus características pueden ser alteradas, pero no así su capacidad operatoria.

- Relacionales: no se encuentran entre elementos (materiales corpóreos, u objetos y sujetos); en esta espacialidad no hay más que relaciones de fuerza correspondiéndose unas a otras.

- Móviles: si, en algún momento, su permanente movimiento no es percibido, se tratará de alguna especie de apariencia, ya que en realidad siguen ejerciendo sus fuerzas (será cuestión de encontrar el nivel preciso donde el movimiento puede ser percibido).

- Inestables: están en constante conflicto por lo que la fuerza de su estabilidad es ínfima (aunque pueda ser duradera).

- Desequilibradas: las fuerzas que entran en conflicto no se destruyen entre sí, por lo que su «completo» equilibrio no existe; se trata de una perpetua (des)equilibración.

XXI, 2002, p. 113. Foucault agrega en la misma página que el poder «se está produciendo a cada instante, en todos los puntos, o más bien en toda relación de un punto con otro. El poder está en todas partes; no es que lo englobe todo, sino que viene de todas partes» (Ibid); y, en otro lugar: «al forjar otra teoría del poder, se trata, al mismo tiempo, de forjar otro enrejado de desciframiento histórico» (Ibid, p. 111). 
- Desiguales: las relaciones con las que entran en contacto, así como las cercanías y lejanías que hay entre ellas, van tejiendo diversas formas históricas y haciendo posible diferentes intensidades para cada relación.

- Heterogéneas: al definirse por el lugar que ocupan con respecto a las otras (y ninguna, lógicamente, ocupa el mismo y exacto lugar), son todas diferentes; incluso, a través de los distintos niveles existentes se desintegraría la posible correspondencia entre relaciones aparentemente similares.

- Locales: van tejiendo sus formas e intensidades de acuerdo al lugar que ocupan en relación con las otras relaciones; pero siempre en el ámbito de su especificidad local.

- Directas: su manera de entrar en conexión con las otras relaciones es en forma directa (no hay nada que funcione como medio, ni nadie que sea intermediario).

- Productivas: la permanente y directa conexión de una relación con otra es sinónimo de producción de otras relaciones, las cuales, al surgir, entran inmediatamente en conexión con todas las otras; por eso Foucault dice de ellas que son «matrices de transformaciones». ${ }^{19}$

- Intencionales: estas relaciones de fuerza no son subjetivas, no remiten a un sujeto, ni a una reflexión, ni a un modo de pensar, ni a una conciencia, ni a una razón (por eso es que nadie las concibe). Con la utilización que hace Foucault de la palabra «intención», se podría sospechar que, a través de la misma, hace cierta referencia al ejercicio de la voluntad. Sin embargo, es preciso situar aquí otra acepción del término «intención» que matiza la idea interior, la cual refiere a una especie de «instinto». Situando este análisis en relación a lo que ya explicitó Foucault en La verdad y las formas jurídicas, respecto de la conciencia como un mero refinamiento del instinto ${ }^{20}$, esta característica intencional de las relaciones de fuerza toma mayor claridad: relaciones que, en tanto instintos, se abren lugar ejerciendo irremediablemente su fuerza.

- Anónimas: no hay un individuo o grupo de individuos que puedan crearlas -ni siquiera que puedan crear sus efectos- de forma soberana; es decir, aquí no hay concepción legítima que pueda concebir para un sujeto la omnipotencia del control sobre esta espacialidad relacional; su lógica de aparición y funcionamiento es totalmente otra.

Ahora bien, es preciso delinear las especificidades del juego -la lógica-que se desarrolla en esta espacialidad de las relaciones de fuerza:

- Hay una multiplicidad de relaciones de fuerza.

19 Ibid, p. 121

$20 C f$. M. Foucault, La verdad y las formas jurídicas. Barcelona: Gedisa, 2003, pp. 9-33. 
- Éstas se encuentran en un permanente e incesante enfrentamiento.

- Las relaciones de fuerza están siempre a distancia de -conectadas conotras (nunca son literalmente extrañas unas a otras), aunque ello implique mayores o menores grados de lejanía -o cercanía. No conectan puntos, ni elementos -ni objetos, ni sujetos- que tendrían cierta preeminencia, cierta soberanía, cierta preexistencia o cierta permanencia dada de antemano; sólo hay relaciones o distancias entre otras relaciones o distancias; por lo que el investigador sólo podrá analizar entramados o dominios de relaciones.

- Estas relaciones de fuerza en conflicto producen determinados estados de tensión, en cuyos efectos nosotros luego solemos intentar captar sujetos y objetos para conformar nuestra comprensión del mundo. Sin embargo, será preciso ejercer una concepción tal que pueda permanecer en las tensiones, y allí las analice, sin caer en reducciones.

Más allá de cualquier extraña apariencia que podamos percibir producto de determinada concepción que aún hoy nos domina, diremos que esta espacialidad foucaulteana está conformada por el juego de enfrentamientos incesantes entre una multiplicidad de relaciones de fuerza (entendiendo a éstas, no como elementos, sino como fuerzas que habitan distancias, las cuales no unen elementos sino nuevas distancias o fuerzas que pensar), de los cuales surgen permanentemente determinadas tensiones que se perciben como efectos.

Cuando ciertas relaciones entran en conflicto y, por su juego de fuerzas, «se estabilizan» o «se inmovilizan», sería de sospechar que allí se formó algo así como un poder, una resistencia, un elemento, un objeto y su sujeto,-en definitiva- una forma que es posible apreciar por su falta de movimiento.

En virtud de esas formas que apenas podemos percibir es que utilizamos estrategias para situarnos en lugares diferentes dentro de lo que podríamos llamar el campo socio-político. Sin embargo, a pesar de las apariencias (y ésta quizás sea un de las grandes enseñanzas de Foucault), no debemos alejarnos de la concepción antes desarrollada de la espacialidad y su permanente tensión producida por el ejercicio de relaciones de fuerzas en conflicto.

Las necesidades utilitaristas en las cuales nos solemos apoyar para tener esa comprensión de lo social -como elementos, con objetos y sujetos- se podrían ver realmente perjudicadas si agudizáramos la crítica sobre algunos de los fracasos revolucionarios (o al menos llamados así) del último siglo. Es cierto que resulta más fácil atacar al «Estado» entendiéndolo como un elemento, que como una especie de efecto virtual dibujado por una determinada matriz de relaciones en tensión (vale aclarar: no por ello menos eficaz). A pesar de las facilidades que arroja aquella concepción, se debería reflexionar sobre su utilización, ya que nos habilita o nos induce a concebir un claro objeto para un efectivo ataque, pero no a aquello que realmente es el Estado: si bien satisface 
la demanda de un «blanco de ataque», éste no resulta efectivamente real o útil a los fines -últimos- que se persiguen.

Será necesario continuar reelaborando las concepciones hasta ahora utilizadas, ya que la historia se ha encargado, una y otra vez, de enfrentarnos con pruebas de diverso tipo, las cuales señalan que la tangibilidad teóricopráctico-política de la entidad de «lo real», al menos hasta ahora, fue invisible a los ojos.

Se debe dejar en claro que no estamos refiriendo a un mundo imaginario que no podríamos observar. Por el contrario, la intención es que los ojos abandonen la mirada soberana creadora de objetos y sujetos, y hagan hincapié en lo que realmente observan cuando lo hacen: es decir, el lugar que determinado «aparente objeto»-o, más bien, deberíamos decir «el lugar que determinada matriz de relaciones»- ocupa en relación a los otros de su misma especie, el lugar que ocupa en relación a aquello que lo rodea, los discursos de los cuales forma parte, los seres que se instalan en él, que lo representan, que le dan sentido, que lo cuestionan, los símbolos que le dan entidad, su historia o, mejor dicho, sus historias. En definitiva, se trata de comprender sin objetivar, ni reducir, y de no creer que lo que se nos presenta como dado se encuentra exento de construcción o de una concepción y un vocabulario que lo sostenga como tal, es decir, como «aparentemente se presenta».

Lo que aquí destacamos del proyecto foucaulteano es que hace visible e insiste en que mirar es un proceso complejo: se trata de hacer lugar a una complejización de la mirada y, tal vez, poder realizar una crítica a las acciones que se vieron fundamentadas -y así reducidas- por aquella otra concepción.

Cuando Foucault menciona la aparición de determinadas prácticas-discursivas, no deja de hacer referencia a sus respectivos orígenes o nacimientos como si fueran efectos - nunca del todo estables- de determinadas matrices de relaciones que se encuentran en tensión. ${ }^{21}$ A través de la proliferación, innovación, anexación, invención o penetración, estas relaciones de fuerza van tejiendo dispositivos que penetran el cuerpo de lo social. Es en esta red superficial como «campo múltiple y móvil de relaciones de fuerza donde se producen efectos globales, pero nunca totalmente estables, de dominación».22

En efecto, en tanto que las relaciones de poder y de saber conformarían una especie de dimensión ontológica, una espacialidad ontológica, deberíamos indagar si efectivamente esta espacialidad podría ser concebida como una ontología-política-del presente.

21 Cf. M. Foucault, Historia de la sexualidad 1, pp. 130-132.

22 Ibid, p. 124. 
En el texto denominado «El sujeto y el poder» (inédito hasta 1982), Foucault nos ofrece numerosas pistas para poder continuar (des)cifrando la dimensión espacial; la cual, como es preciso recordar, es considerada previa a las concepciones del tiempo cronológico y del espacio en tanto mirada soberana en las que nos movemos estratégicamente. Afirmará que las explicaciones realizadas sobre las relaciones de poder que habitan en dicha espacialidad no pretenden ser una descripción de algunos «efectos» 0 «manifestaciones», ni tampoco evadir la argumentación a favor o en contra de posibles «orígenes» $\mathrm{o}$ «causas», $\mathrm{y}$, menos aún, omitir la explicitación de una supuesta naturaleza básica de lo que allí sucedería; se trata, nos aclara Foucault, de poner en suspenso la existencia del poder e intentar presentar la cuestión de una manera diferente y, a su vez, legítima; se trata de unificar la explicación sobre el «qué», el «por qué» y el «cómo» (a diferencia de la conceptualidad clásica que los entiende como pertenecientes a ámbitos separados), y evitar así una ontología que sea fraudulenta. ${ }^{23}$ Eso es justamente lo que -consideramos- esta «espacialidad» intenta llevar a cabo; de ahí, también, su estricto carácter político.

Especificando la lógica de esta gran unidad espacial, Foucault nos dice que: «lo que define las relaciones de poder es un modo de acción que no actúa directa e inmediatamente sobre los otros. En cambio, actúa sobre sus acciones: una acción sobre una acción, sobre acciones existentes u otras que pueden suscitarse en el presente y en el futuro. [...] Es una estructura total de acciones dispuestas para producir posibles acciones: incita, induce, seduce, facilita o dificulta». ${ }^{24}$ Atendiendo a la complejidad de la cita expuesta es preciso analizar dos puntos centrales de la dinámica espacial -ontológica y política- descrita:

El primero de ellos es que, en esta espacialidad, no hay elementos (ni objetos ni sujetos) desde los cuales pueda partir tal o cual acción, ni tampoco algunos a donde llegar o en donde poder influir. Aquí, todo es movimiento: una acción sobre una acción, movimiento sobre movimiento, -en definitiva- relación sobre otra relación. Es necesario, entonces, comprender el término «acción» como una relación de fuerza que se ejerce; por lo que, en esta espacialidad, sólo hay relaciones ejerciendo sus fuerzas sobre otras relaciones que, a su vez, se encuentran operando del mismo modo.

El segundo punto se trata de la referencia que hace Foucault a un tipo de «acciones» que podrían existir o no, y que podrían suscitarse en el presente o en el futuro. En esta espacialidad, parecería ser posible accionar (habría que decir, según hemos visto, ejercer una relación de fuerza) sobre una acción (es decir: sobre otra relación de fuerza) que aún no existiría. Asimismo, se hace

$23 C f$. M. Foucault, «El sujeto y el poder», en H. L. Dreyfus y P. Rabinow, op. cit., pp. 249-250.

24 Ibid, p. 253. 
mención de acciones que, si bien no existen, podrían suscitarse en el presente; lo cual inmediatamente nos induce a suponer que su concepción del presente no es aquélla solidaria del instante-presente como punto geométrico inextenso. Debido a la fugacidad que implanta esa concepción temporal, no sería factible concebir la posibilidad de que, en esa misma y precisa medida de tiempo (fugaz e instantánea), algo que no tenga existencia, a su vez, esté suscitándose. Se requiere, para ello, de otra concepción del tiempo presente (si es que se debe continuar llamándolo así); se necesita una perspectiva con otra apertura temporal, la cual quizás sea posible pensar a partir de la espacialidad aquí referida.

De todas maneras, lo que resulta especialmente problemático es la doble posibilidad de actuar sobre algo que no existe (sobre acciones inexistentes) y sobre acciones que, si bien uno puede intentar prever, no están aquí como para ejercer algún tipo de acción directa sobre ellas (es decir, sobre acciones -o relaciones de fuerza- futuras). Evidentemente (y aquí ya sustituyendo el término «acción» por el de «relación de fuerza», de forma tal de ser más precisos), la única manera de comprender la posibilidad de que una relación ejerza su fuerza sobre otra relación que aún no existe, o sobre otra con la cual aún no entró en contacto, es reformulando las concepciones -hasta ahora utilizadas- de espacio (recortado por una mirada soberana) y de tiempo (distribuido y acumulado cronológicamente), por otras que sean más afines a esta espacialidad relacional que estamos visualizando. En ese sentido, quizá resulte de mayor precisión comenzar a pensar aquello que usualmente llamamos «espacio» y «tiempo», ya no como separados, sino fundidos en una especie de dimensión única: en una espacialidad relacional en donde diversas temporalidades sean posibles.

Será preciso, entonces, prestar especial atención a una de sus características primordiales: la espacialidad como mundo de lo posible. «El ejercicio del poder consiste en guiar las posibilidades de conducta y disponerlas con el propósito de obtener posibles resultados». ${ }^{25}$ Es decir que las relaciones, al ejercer sus fuerzas contra aquéllas provenientes de otras relaciones, constituyen el juego mediante el cual se abren y se cierran puertas a lo posible. Es necesario volver a concebir la posibilidad, en sí misma, como una instancia real (en el sentido de que opera en «lo real»), inteligible y plenamente política. ${ }^{26}$

\section{IV}

Foucault se encargará de señalar el modo en que aquello que conocemos bajo el nombre de «gobierno» ha intentado ubicar las relaciones de fuerza bajo su manto. En ese sentido, aclarará que estas últimas no pertenecen a una esfera 
supra socio-política (a partir de la cual dirigir), ni a una dimensión infra sociopolítica (desde donde tejerlo todo). Las relaciones de poder y de saber son-ellas mismas- lo socio-político. Justamente por eso resulta sumamente interesante prestar atención a los lugares en donde ellas se manifiestan.

Se entiende, así, el interés de Foucault por las instituciones y sus diversas racionalidades. Especialmente en el mundo moderno, el cuerpo de lo social se ha visto atravesado de parte a parte por este proceso de fuerte institucionalización. Aún hoy observamos los vínculos entre aquello que entendemos como lo social y el mundo institucional; bajo una simple mirada, ellos parecen confundirse. Lo interesante es que esta apariencia trae aparejada otra, la cual indicaría que las racionalidades de este mundo institucional-social, serían similares a aquéllas de las relaciones. Sin embargo, eso no es estrictamente cierto, ya que esta racionalidad institucional sería un efecto posible y determinado, entre todos los que habilitarían la espacialidad relacional (ello, en tanto dimensión de lo posible).

Asimismo, Foucault advertirá sobre los complejos efectos que produce el extraño y complejo vínculo entre el Estado, las instituciones, los modos de vida y -finalmente- la dimensión espacio-relacional. No es que haya entre ellos una especie de sucesiva complementación o un apoyo escalonado; pero sí podemos observar que algunas articulaciones (y las prácticas-discursivas que en ellas circulan) logran consolidar, solidificar, construir y situar determinados «estados de tensión» entre las relaciones de fuerza, impidiendo una mayor circulación (es decir, limitando el circuito de relaciones de poder y de saber de acuerdo a temporalidades diversas).

Para Foucault, éste es uno de los núcleos problemáticos más importantes; justamente por eso se animará a señalar el siguiente enunciado propositivo: «La conclusión podría ser que el problema político, ético, social, filosófico de nuestros días no sea tratar de liberar al individuo de las instituciones del Estado, sino de liberar a ambos del Estado y del tipo de individualización que se vincula con el Estado. Tenemos que promover nuevas formas de subjetividad a través de esta especie de individuación que nos ha sido impuesta por varios siglos». ${ }^{27}$

Unas páginas antes Foucault había enunciado que, si bien (y por lo general), una sociedad siempre está llevando adelante luchas contra las formas de dominación -étnicas, sociales, religiosas-, contra las formas de explotación y contra las formas de sujeción o subjetividad, se podría afirmar para cada época una correspondencia especial con alguno de estos tipos de lucha (dependiendo de cuál sea la que resalte en cada época). ${ }^{28}$ Como resulta claro de sus trabajos, Foucault aboga para su época una firme posición a favor de la última de las formas de lucha enunciadas: las de la subjetividad.

27 Ibid, p. 249.

28 Cf. ibid, p. 245. 
Sin embargo, lo central de la cita expuesta es que, a pesar de haber puesto al descubierto la lógica operativa del mundo institucional moderno, allí desvincula de cierta «responsabilidad» a las instituciones, y llama a independizarlas del Estado; según hemos visto, este último parecería ser quien recorta excesivamente el circuito de las relaciones de poder y de saber, delimitando, así, el mundo de lo posible.

En nuestro caso, consideramos prudente distanciarnos de esos enunciados propositivos y focalizar el trabajo en el modo en que se conciben y -así- se gestionan las relaciones de fuerza. Foucault nos ayudará en ese sentido al advertir «que las relaciones de poder han sido progresivamente gubernamentalizadas, es decir, elaboradas, normalizadas y centralizadas en la forma, o bajo los auspicios, de instituciones estatales». ${ }^{29}$

Según lo hemos visto, este proceso de elaboración, normalización y centralización de las relaciones de fuerza por parte de la gubernamentalidad parecería haber requerido -y aún parece requerir-, de manera casi indispensable, la gestión articulada por «el eje con forma de cuchillo» que implementaría el gobierno: nos referimos a la concepción de tiempo cronológico, y a su correlativo espacio objetual -construido a través de una «eficiente» mirada soberana.

¿Serán estas concepciones espacio-temporales, sino los últimos, al menos sí unos de los más ocultos y profundos resabios de la lógica socio-política del orden existente?

Solamente una larga y profunda investigación podrá comenzar a poner al descubierto, no sólo los orígenes espacio-temporales de nuestra civilización, sino también las implicancias políticas más radicales que dichas concepciones traen consigo. 
FERNANDO BERESÑAK pertenece al UBACyT - Instituto de Investigación Gino Germani (FSOC-Universidad de Buenos Aires, Argentina).

\section{Publicaciones recientes:}

«Aproximaciones críticas a la conformación de la ciudadanía y del espacio político en la obra de Immanuel Kant», Revista Pléyade. Revista de Análisis e Investigación Política, Año III, Número 5 (Primer Semestre 2010), ISSN 0718-655X, páginas 251-277.

«El exilio y el encierro como problemática espacial», en M. Burello, F. Ludueña Romandini, y E. Taub (Compiladores), Políticas del exilio. Orígenes y vigencia de un concepto. Buenos Aires: EDUNTREF, en prensa (julio 2011).

Línea de investigación:

La temática de investigación de su doctorado -en curso- en la Facultad de Ciencias Sociales de la Universidad de Buenos Aires es la noción de sujeto político en las obras de Gilles Deleuze, Jacques Derrida y Michel Foucault, a partir de las concepciones espaciales y temporales por ellos problematizadas.

Correo electrónico: beresnakfernando@hotmail.com 